\title{
A child with a severe headache: Questions
}

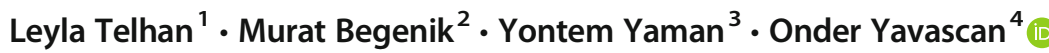

Received: 28 September 2020 / Revised: 15 November 2020 / Accepted: 5 January 2021 / Published online: 1 March 2021

(C) IPNA 2021

Keywords Child $\cdot$ Headache $\cdot$ Sinusitis $\cdot$ Hepatosplenomegaly $\cdot$ Hypertension $\cdot$ Proteinuria $\cdot$ Hematuria

\section{Case report}

A 12-year-old girl presented with complaint of severe headache lasting 10 days, nausea and vomiting for 1 day. The headache was localized in the right fronto-occipital region with spread to the neck and shoulders. In her medical history, tympanostomy tubes were inserted in her ears due to frequent otitis media with effusion before 2 years. She had recurrent reactive airway, asthma attacks, and allergic rhinitis. Before the definitive diagnosis could be established, she had received systemic antihistamine, nasal steroid, leukotriene antagonist, inhaler steroid, and salbutamol. She was treated with sefaclor per orally due to acute sinusitis for 5 days. The patient was admitted to our hospital with symptoms of severe headache. Physical examination showed that she was alert with an axillary temperature of $36.3^{\circ} \mathrm{C}$, weight of $60\left(95^{\text {th }}\right.$ percentile) $\mathrm{kg}$, height of 155 (65th percentile) $\mathrm{cm}$, blood pressure of $150 / 100 \mathrm{mmHg}(>95 \mathrm{th} />$ 95th percentile), and heart rate of 98 beats/min. Examination revealed pallor and hepatosplenomegaly (liver span $2 \mathrm{~cm}$ and palpable spleen size of $1 \mathrm{~cm}$ ). An ophthalmologic examination showed bilateral grade 2 papilledema but visual acuity and visual fields were normal. Neurological examination was normal.

The answers to these questions can be found at https://doi.org/10.1007/ s00467-021-04932-0.

Onder Yavascan

oyavascan@hotmail.com.tr

Leyla Telhan

ltelhan@medipol.edu.tr

Murat Begenik

mbegenik@medipol.edu.tr

Yontem Yaman

yyaman@medipol.edu.tr
In the laboratory work-up, WBC: $10.890 / \mathrm{mm}^{3}, \mathrm{Hb}: 6.8 \mathrm{~g} / \mathrm{dl}$, Htc: 18.7\%, MCV: 85 fl, PLT: 463,000/ $\mathrm{mm}^{3}$, ESR: 98 mm/h, and reticulocytes: $2.5 \%$ as well as mild proteinuria (++) and hematuria (10-12 erythrocytes $/ \mathrm{mm}^{3}$ ) in urinalysis, with urinary protein quantification of $1495 \mathrm{mg} /$ day $\left(65 \mathrm{mg} / \mathrm{m}^{2} / \mathrm{h}\right)$. Biochemical markers of kidney function, electrolytes, total protein, albumin, serum lipids, and the liver function were within normal limits. The findings of brain magnetic resonance images were normal.

\section{Questions}

1. What is your suspected diagnosis of acute severe headache in this patient?

2. What additional tests would you obtain to help confirm this diagnosis and to investigate etiologic causes, considering other symptoms?

3. How would you manage this patient?

Publisher's note Springer Nature remains neutral with regard to jurisdictional claims in published maps and institutional affiliations.

1 Pediatric Intensive Care, Faculty of Medicine, Istanbul Medipol University, Istanbul, Turkey

2 Pediatrics, Faculty of Medicine, Istanbul Medipol University, Istanbul, Turkey

3 Pediatric Hematology, Faculty of Medicine, Istanbul Medipol University, Istanbul, Turkey

4 Departments of Pediatric Nephrology, Faculty of Medicine, Istanbul Medipol University, Istanbul, Turkey 